\title{
Yurtta Kalan Üniversite Öğrencilerinin Duygu Düzenleme ile Öz- Şefkat Düzeyleri Arasındaki İlişkinin İncelenmesi
}

\author{
Saliha Günn $^{1}$ (i) Osman Oğulcan Türkmen² (iD) S. Barbaros Yalçın ${ }^{3}$ \\ Psikolojik Danışman, MEB Sultan Alparslan İmam Hatip Ortaokulu, Konya, Türkiye \\ saliihagun@gmail.com (Sorumlu Yazar/Corresponding Author) \\ ${ }^{2}$ Öğr. Gör., Gümüşhane Üniversitesi, Kelkit Sağlık Hizmetleri Meslek Yüksekokulu, Çocuk Bakımı ve Gençlik Hizmetleri Bölümü, Gümüşhane, \\ Türkiye osmanturkmentr@gmail.com \\ ${ }^{3}$ Doç. Dr., Necmettin Erbakan Üniversitesi, Ahmet Keleşoğlu Eğitim Fakültesi, Rehberlik ve Psikolojik Danışmanlık Anabilim Dalı, Konya, \\ Türkiye barbarosyalcin@erbakan.edu.tr
}

\begin{tabular}{|c|c|}
\hline Makale Bilgileri & ÖZ \\
\hline $\begin{array}{l}\text { Anahtar Kelimeler: } \\
\text { Duygu, } \\
\text { Duygu düzenleme, } \\
\text { Öz-şefkat. }\end{array}$ & $\begin{array}{l}\text { Bu araştırmanın amacı yurtta kalan üniversite öğrencilerinin duygu düzenleme ile öz-şefkat düzeyleri arasındaki } \\
\text { ilişkinin incelenmesidir. Araştırmanın çalışma grubunu, } 260 \text { 'ı kadın ve } 145 \text { 'i erkek olmak üzere toplam } 405 \\
\text { yurtta kalan üniversite öğrencisi oluşturmaktadır. Araştırmada veri toplama araçları olarak kişisel bilgi formu, } \\
\text { Duygu Düzenleme Ölçeği ve Öz-Duyarlık Ölçeği kullanılmıştır. Araştırmanın amaçlarını test etmek üzere } \\
\text { verilerin analizinde Pearson Momentler Çarpımı Korelasyonu, Çoklu Doğrusal Regresyon Analizi ve Bağımsız } \\
\text { Gruplar t Testi kullanılmıştır. Analiz sonuçları incelendiğinde; duygu düzenlemenin yeniden değerlendirme alt } \\
\text { boyutunun öz-şefkatin alt boyutlarından öz sevecenlik ve bilinçlilik düzeyleri ile orta düzeyde pozitif yönlü, } \\
\text { paylaşımların bilincinde olma alt boyutu ile düşük düzeyde pozitif yönlü ilişki bulunmuştur. Duygu } \\
\text { düzenlemenin gizleme alt boyutunun öz sevecenlik, paylaşımların bilincinde olma ve bilinçlilik düzeyleri ile orta } \\
\text { düzeyde pozitif yönlü, öz-yargılama, izolasyon ve aşırı özdeşleşme düzeyleri ile de düşük düzeyde negatif yönlü } \\
\text { ilişki bulunmuştur. Öz-şefkatin; öz sevecenlik, öz-yargıllama ve bilinçlilik alt boyutları yeniden değerlendirme alt } \\
\text { boyutunu anlamlı bir şekilde yordamaktadır ve bu alt boyutların, yeniden değerlendirmenin toplam varyansının } \\
\text { \%16.1'ini açıklamaktadır. Öz-şefkatin; öz sevecenlik, bilinçlilik ve aşırı özdeşleşme alt boyutları gizleme alt } \\
\text { boyutunu anlamlı bir şekilde yordamaktadır ve bu alt boyutların, gizlemenin toplam varyansının \%22.9'unu } \\
\text { açılklamaktadır. Cinsiyet açısından ele alındığında da duygu düzenlemenin yeniden değerlendirme alt boyutunun } \\
\text { erkeklerde daha yüksek düzeyde olduğu görülmektedir. }\end{array}$ \\
\hline
\end{tabular}

\section{Examination of the Relationship Between Emotion Regulation and Self- Compassion Levels of University Students Who Are Staying in the Dormitory}

\begin{tabular}{|c|c|}
\hline Article Info & ABSTRACT \\
\hline $\begin{array}{l}\text { Article History } \\
\text { Received: } 07.05 .2020 \\
\text { Accepted: } 05.10 .2020 \\
\text { Published: } 28.12 .2020 \\
\text { Keywords: } \\
\text { Emotion, } \\
\text { Emotion regulation, } \\
\text { Self-compassion. }\end{array}$ & $\begin{array}{l}\text { The proposed aim of this study is to examine the relationship between emotion regulation and self-compassion } \\
\text { levels of university students who are staying in the dormitory. The study group of the research consists of } 405 \\
\text { university students, } 260 \text { of whom are females and } 145 \text { of whom are males.Personal information form, Emotion } \\
\text { Regulation Scale and Self-Compassion Scale were used in the data gathering process.In order to examine the } \\
\text { objectives of the study, Independent Samples t-Test, Pearson Product-Moment Correlation, and Multiple Linear } \\
\text { Regression Analysis were used to analyze the data. When the results examined, it is found that the relationship } \\
\text { between the cognitive reappraisal subscale of emotion regulation and self-kindness and mindfulness which are } \\
\text { subscales of self-compassion is medium-level-positive, and between the subscale of common humanity is low- } \\
\text { level-positive.In addition, the expressive suppression subscale of emotion regulation; was found to be medium- } \\
\text { level positively related to self-kindness, common humanity and mindfulness levels and it found to be low-level } \\
\text { negatively related with self-judgment, isolation, and over-identification.Self-kindness and mindfulness subscale } \\
\text { of self-compassion enable us to interpret cognitive reappraisal subscale meaningly and thus it explains \% } 16.1 \text { of } \\
\text { the total variance of cognitive reappraisal of those subscales.Self-kindness, mindfulness and over-identified } \\
\text { subscales of self-compassion enable us to interpret expressive suppression subscales meaningly and those } \\
\text { subscales explain \% } 22.9 \text { of total variance of expressive suppression. When it is taken into account from gender } \\
\text { perspective, it can be seen that the cognitive reappraisal subscale of emotion regulation is higher in men. }\end{array}$ \\
\hline
\end{tabular}

Attf/Citation: Gün, S. Türkmen, OO. Yalçın, SB. (2020). Yurtta Kalan Üniversite Öğrencilerinin Duygu Düzenleme ile Öz-Şefkat Düzeyleri Arasındaki İlişkinin İncelenmesi, Ahmet Keleşoğlu Eğitim Fakültesi Dergisi, 2(2), 166-180. 


\section{GİRIŞ}

Üniversite hayatına adım atmak birçok öğrenci için yeni yaşantılarla karşılaşmak anlamına gelmektedir. Bununla birlikte pek çok öğrenci bu başlangıcı; doğduğu, ilk ve orta öğrenimini tamamladığı ilden ayrılarak, ailesinden uzak bir alanda yaşayarak gerçekleştirmektedir. Yeni yaşam alanı öğrenci yurtları olan gençler, birtakım sorun ve sorumluluklarla karşı karşıya kalmaktadır (Sürücü ve Bacanlı, 2010). Yıldırım (2014) tarafından yapılan çalışmada öğrencilerin yurtlarda karşılaştıkları problemler sosyal, psikolojik, eğitsel, fiziksel olmak üzere 4 boyutta ele alınmıştır. Belirlenen bu dört boyut altındaki problemler arkadaşlık, aile baskısı, sınav stresi, çevreye uyum, zaman baskısı, korku, sürekli çalışma, gürültü, eksik kazanımlar, temizlik, çalışma odası, havalandırma olarak ortaya koyulmuştur. Bununla birlikte öğrencilerin mesleki ve yetişkinlik hayatına hazırlandıkları üniversite yıllarında, problemleriyle başa çıkabilen, çevresel ve içsel koruyucu etkenlerin bilincinde olan, hayata aktif katılım sağlayan, iletişim becerilerini kullanabilen ve bunları amaçları, hedefleri doğrultusunda işlevsel olarak kullanabilen bireyler olmaları beklenmektedir (Gökçen, 2015). Üniversite öğrencilerinin bu beklentileri gerçekleştirebilmesinde, bu becerileri edinebilmesinde duygu düzenleme ve öz-şefkatin önemli rollerinin olduğu düşünülmektedir.

Bütün bireyler insanlık tarihi boyunca duygulara sahip olmuşlardır. Bireyler kendi duygularının farkında olmasıyla birlikte çevresindeki bireylerin de duygularının farkında olarak hayatlarını devam ettirmektedirler. Kişiler, sosyal yaşamdaki ilişkilerini de çevresindekilerin duygularını gözeterek düzenlerler (Karaçay, 2018). Türk Dil Kurumu duygu kavramını; duyularla algılama, his, belirli nesne, olay veya bireylerin insanın iç dünyasında uyandırdığı izlenim, önsezi, nesneleri veya olayları ahlaki ve estetik yönden değerlendirme yeteneği olmak üzere çeşitli şekillerde ifade ederken, (Türk Dil Kurumu, 2019). Oxford İngilizce Sözlüğü ise duyguyu herhangi bir zihin, his, tutku çalkantısı ya da devinimi; herhangi bir şiddetli ya da uyarılmış zihinsel durum olarak belirtmiştir. Amerikalı psikolog Daniel Goleman ise duyguyu bir his ve bu hisse özgü belirli düşünceler, psikolojik ve biyolojik haller ve bir dizi hareket eğilimi olarak tanımlamıştır (Goleman, 1998). Tanımlara bakıldığında duyguların; kısa süreli, kişilerin kendi iç dünyalarında ne hissettiğini anlamalarına yardımcı olan ve bu içsel süreci göz önünde bulundurarak yaşamlarını düzenlemelerini sağlayan, fiziksel, bilişsel ve nöropsikolojik boyutta bireyleri harekete geçiren dürtüler olduğunu söylemek mümkündür (Aktaş, 2017; Goleman, 1998; Gündüz, 2016). Araştırmacılar tarafından beyin ve beden yeni yöntemlerle incelendikçe tüm duyguların bedeni farklı farklı tepkilere nasıl hazırladığına yönelik artış gösteren fizyolojik detaylar ortaya konmaktadır (Goleman, 1998).

Duyguların yönlendirici ve değerlendirici olmak üzere iki fonksiyonu vardır. Bu fonksiyonlar bireylerin harekete geçmesi için enerji sağlamayı ve bireylerin gereksinimlerini giderebilmeyi amaçlamaktadır. Kişinin gereksinimleri karşılanıyorsa olumlu, karşılanmıyorsa olumsuz duygular ortaya çıkabilir. Bunun üzerine kişiler hayatlarını belirli duyguları yaşamak ve belirli duygularla da aralarına mesafe koyabilmek üzere yönlendirmektedirler (Aktaş, 2017; Karaçay, 2018). Bireyler olumsuz duygu hissettiğinde, bu duygudan uzaklaşmayı arzu eder. Bu da bireyi hissettiği duygunun yoğunluğunu artırıp, azaltmaya veya duyguyu devam ettirmeye yönlendirebilir (Werner ve Gross, 2010). Duyguların; bireyin kendisi ya da diğerleri için olumsuz neticelere sebep olma ihtimali, acı verici olarak değerlendirilmesi, toplumsal normlara ve sosyal beklentilere uygun davranışlar göstermeye çalışmak ve diğerlerini koruma gibi nedenlerle insanlar duygularını düzenleme ihtiyacı hissetmektedirler. Başka bir deyişle haz veren, olumlu duygular deneyimleme gereksinimi ve acıdan kaçınma bireyleri duygularını düzenlemeye güdülemektedir (Niedenthal ve diğ., 2006; Akt. Küçüker, 2016). Tam bu noktada literatüre yakın zamanda girmiş olan duygu düzenleme kavramı karşımıza çıkmaktadır (Aktaş, 2017; Cole, Dennis ve Martin, 2004). 
Duygu düzenleme kavramı, bireyler tarafından hissedilen duyguların tanınmasını, duyguların kabul edilmesini, hangi süreçlerde hangi duyguların ne kadar hissedileceği, nasıl tecrübe edileceği ve duyguların nasıl dışa vurulacağından sorumlu tüm içsel ve dişsal süreçleri ifade etmektedir (Gratz ve Roemer, 2004; Gross, 1998). Bireyler duygu yönetimini nasıl yapacaklarını eski devirlerden beri merak etmişlerdir (Gross, 1998). Duygu düzenleme hem olumlu hem olumsuz duygular için uygulanmaktadır (Gross ve Munoz, 1995). Bununla birlikte duygu düzenleme becerileri davranışsal ya da zihinsel kontrol yoluyla en çok duygusal uyarılmayı özellikle olumsuz duyguları azaltmak için kullanılmaktadır (Gross, 1998; Thompson, 2008). Kişi duygu düzenlemeyi kullanarak; kendisini kötü hissetmesine yol açan bir duyguyu deneyimlediğinde, bu kötü hissetme sürecini rahatsız olmayacak bir hale getirmeye çalışır (Leahy, Tirch ve Napolitano, 2011). Duygusal düzenleme, duygusal uyarılmay1 sürdürmeyi ve geliştirmeyi, onu engellemeyi ya da bastırmayı içerebilir (Thompson, 2008). Böylece kişi etkilenme düzeyini azaltıp, arttırabilir ya da duyguyu sürdürmektedir. Bu sayede kişi başa çıkma ve yeniden düzenleme sürecine gidebilmektedir (Leahy, Tirch ve Napolitano, 2011). Duygularını yönetimini yapabilen bir birey, duygusal tepkilerini özellikle de duyguların şiddetini ve geçici niteliklerini kendi amaçları doğrultusunda gözlemler, değerlendirir ve tanzim eder. Duygu düzenleme, yalnızca edinilen duygunun kendini yönetme stratejilerini değil, aynı zamanda duygunun düzenlendiği dış etki çeşitlerini de kapsar. Bunun nedeni, başkalarının müdahaleleriyle önemli miktarda duygusal düzenleme yapılmasıdır (Thompson, 2008).

Duygu fizyolojik uyarılma, nörolojik aktivasyon, bilişsel değerlendirme, dikkat süreçleri ve tepki eğilimlerini içeren çok yönlü bir fenomen olduğundan, duygunun yönetimine yönelik çeşitli yollar vardır (Thompson, 2008). Duygu düzenlemeyi açıklamak üzere yaygın olarak kabul edilen stratejilerden birisi Gross (1998) tarafından öne sürülen süreç modelidir. Bu model; durum seçimi (situation selection), durum değiştirme (situation modification), dikkatte yayılma (attentional deployment), bilişsel değişim (cognitive change) ve tepki düzenleme (response modulation) olmak üzere duygu düzenlemenin beş ailesini temsil etmektedir. Durum seçimi, durum değiştirme, dikkatte yayılma ve bilişsel değişim; duyguların ortaya çıkmasından önce kullanılan, herhangi bir olayın duygusal etkisinin değiştirilmesi amacıyla kullanılan öncül odaklı stratejiler olarak sınıflandırılmaktadır (Gross ve Thompson, 2007). Tepki düzenleme süreci ise duygular ortaya çıtıktan sonra kullanılan ve duygusal tepkilerin fizyolojik, yaşantısal ve davranışsal boyutlarda değişmesi amacıyla kullanılan tepki odaklı strateji sınıfında yer almaktadir (Gross, 1998; Gross ve Thompson, 2007).

Vatan (2019a) duygu düzenlemenin bir bütün olduğunu ifade etmekte ve öz-şefkatin duygu düzenleme becerilerinde etkili ve önemli olduğunu vurgulamaktadır. Duygu düzenleme süreçlerinde en derin etki öz-şefkatte deneyimlenebilirken, öz-şefkat duygu düzenleme sürecinde yaşanan güçlüklerle başa çıkmada yardımcı olabilmektedir (Vatan, 2019a). Öz-şefkat bireyin şefkatli tutumlarını kendisine yönlendirmesidir (Yıldırım ve Sarı, 2018). Budizm felsefesini temel alan öz-şefkat, Neff (2003a) tarafından bireyin yetersizlik, acı, üzüntü ve başarısızlık yaşadığı olaylarda kendisine yönelik eleştirilerinde nazik ve anlayışlı olması, olumsuz duygularının bilincinde olarak bu duygularını kabul etmesi ve karşılaşılabilecek olumsuz deneyimlerin insan olmakla ilgili olduğunu bilmesi olarak tanımlanmaktadır.

Öz-şefkat yaklaşımı üç ana bileşeni içermektedir. Birbiriyle etkileşim içinde olan bu bileşenler, kendi içlerinde pozitif ve negatif bir boyut taşımaktadırlar. Bunlar; öz-sevecenliğe karşı öz yargılama, paylaşımların bilincinde olmaya karşı izolasyon, bilinçliliğe karşı aşırı özdeşleşmedir (Akt. Yıldırım ve Sarı, 2018). Öz-sevecenlik bireyin kendisini kınamamasını ve kendisine karşı nazik olmasını, bilinçlilik bireyin kendi duygularına açık ve dikkatli olmasını, paylaşımların bilincinde olma ise acı çekmeyi utanç ve yalnızlık kaynağı olarak görmekten ziyade acı şeyler yaşamanın insan olmanın doğal bir parçası olduğunu, acının evrenselliğini kabul etmektir (Gilbert, 2010). 
Gelişim dönemleri perspektifinden bakıldığında yaşamda öz-şefkat oranının en düşük olduğu evrenin ergenlik dönemi olduğu ortaya koyulmuştur (Neff, 2003a). Bireyler acıyı deneyimlediğinde duygu düzenleme becerilerini kullanmakta zorluk yaşayabilirken, bu süreçlerde ortaya konan öz-şefkat hem duygu düzenleme stratejilerini hem de psikolojik sağllğ ve iyilik halini pozitif olarak etkilemektedir. Öz-şefkat de tüm duygu düzenleme bileşenleri gibi bir beceri olarak kavramsallaştırılmakta ve öz-şefkatin geliştirilebilir bir beceri olduğu düşünülmektedir (Vatan, 2019a).

Vatan (2019b) tarafından duygu düzenleme becerilerini geliştirme üzere yapılandırılmış bir psikoeğitim programında; programın uygulama öncesi ve sonrasında, katılımcıların duygulara yönelik farkındalık, isimlendirme, tanımlama, anlama, değişimleme, kabul, tolerans, duygular ile yüzleşme ve aktif öz-destek için öz-şefkati kullanma becerilerinde anlamlı düzeyde farklılık ve pozitif gelişmeler olduğu ortaya koyulmuştur. Bununla birlikte katılımcılara becerilerden en çok faydalandıkları pratik, alıştırmalar ve hangisini anlamlı buldukları sorulduğunda, öz-şefkat uygulamalarının ön plana çıktığı sonucunun elde edildiği görülmüştür (Vatan, 2019b). Bu doğrultuda özellikle gelişim dönemi olarak risk grubundaki bireylere yönelik duygu düzenleme ve öz-şefkati içerecek olan psikoeğitim programlarının yaygınlaştırılması ve geliştirilmesi sağlanabilir.

Yukarıda yer alan bilgilerden hareketle bu araştırmanın amacı yurtta kalan üniversite öğrencilerinin duygu düzenleme ile öz-şefkat düzeyleri arasındaki ilişkinin incelenmesidir. Bu araştırma kapsamında aşağıdaki sorulara cevap aranmıştır.

1. Yurtta kalan üniversite öğrencilerinin duygu düzenleme ile öz-şefkat düzeyleri arasında anlamlı bir ilişki var mıdır?

2. Yurtta kalan üniversite öğrencilerinin öz-şefkat düzeyleri duygu düzenleme düzeylerini anlamlı olarak yordamakta midir?

3. Yurtta kalan üniversite öğrencilerinin duygu düzenleme düzeyleri cinsiyete göre anlamlı olarak farklılaşmakta mıdır?

\section{YÖNTEM}

Bu bölümde araştırmanın modeli, katılımcılara ilişkin özellikler, veri toplama araçları ve verilerin analizinde kullanılan istatistiksel yöntem ve teknikler hakkında bilgi verilmiştir.

\section{Çalışma Grubu}

Araştırma 2018-2019 eğitim-öğretim yılında Konya ilinde yer alan KTO Eğitim ve Sağlık Vakfı bünyesindeki kız ve erkek öğrenci yurtlarında kalmakta olan üniversite öğrencileri arasından araştırmaya gönüllü olarak katılan yaşları 18-27 arasında değişen 260'1 (\%64,2) kadın ve 145'i $(\% 35,8)$ erkek olmak üzere toplamda 405 kişi ile yürütülmüştür.

\section{Veri Toplama Araçları}

\section{Kişisel Bilgi Formu}

Araştırma kapsamında katılımcılardan bazı kişisel bilgilerin toplanması amacıyla kişisel bilgi formu oluşturulmuştur. Oluşturulan bu formda katılımcıların cinsiyet, yaş ve anne-baba eğitim düzeylerine ilişkin sorular sorulmuştur.

\section{Duygu Düzenleme Ölçeği}

Ölçme aracı yedili derecelendirmede [1 kesinlikle katılmıyorum - 7 kesinlikle katılıyorum] on maddesi bulunup, John ve Gross (2003) tarafından geliştirilmiştir. Bu ölçeğin Türkçe'ye uyarlanması ise Eldeleklioğlu ve Eroğlu (2015) tarafindan gerçekleştirilmiştir. Eldeleklioğlu ve Eroğlu (2015) tarafindan 
Cronbach Alpha kat sayısı yeniden değerlendirme alt boyutu için .78 gizleme alt boyutu için .73 bulunmuştur. Duygu Düzenleme çalışmalarında kullanılabilecek geçerli ve güvenilir bir araç olduğu tespit edilmiştir. Ölçeğin gizleme (suppression) ve yeniden değerlendirme (reappraisal) olarak iki alt boyutu vardır. Ölçeği Türkçe’ ye uyarlayan Eldeleklioğlu ve Eroğlu (2015) yeniden değerlendirme için iç tutarlılık katsayısını .78, gizleme içinse .73 olarak bulmuştur. Test tekrar test katsayılarını ise yeniden değerlendirme için .74, gizleme içinse de .72 olarak belirlenmiştir.

\section{Öz-Duyarlık Ölçeği}

Neff (2003b) tarafindan geliştirilen Öz-Duyarlık Ölçeği'nin orijinal formu 26 madde ve 6 alt boyuttan oluşmaktadır. Alt boyutlar öz-yargılama, paylaşımların bilincinde olma, izolasyon, bilinçlilik, öz-sevecenlik ve aşırı özdeşleşmedir. Ölçek kişilerin kendilerine uygulayabilecekleri öz duyarlık yapısını ölçen bir ölçektir. Ölçek "1 hiçbir zaman”, "2 nadiren”, "3 sık sık", "4 genellikle” ve "5 her zaman" şeklinde 5'li likert tipi bir derecelendirmeye sahiptir. Öz duyarlık ölçeğinin Türkçe’ye geçerlik güvenirlik çalışmalarını Akın, Akın ve Abacı (2007) yapmıştır. Ölçeğin yapı geçerliğgini incelemek amacıyla açımlayıcı faktör analizi (AFA) ve doğrulayıcı faktör analizi uygulanmıştır. Öz-duyarlık Ölçeği'nin iç tutarlık katsayıları ise şöyle sıralanmaktadır; öz-sevecenlik alt ölçeği için .77, öz-yargılama için .72, paylaşımların bilincinde olma için .72, izolasyon için .80, bilinçlilik için .74 ve aşırı özdeşleşme için .74'tür.

\section{Verilerin Analizi}

Bütün değişkenler için betimsel istatistikler hesaplanıp araştırmada yurtta kalan üniversite öğrencilerinin duygu düzenleme ile öz-şefkat düzeyleri arasındaki ilişkiyi ortaya koymak amaçlanmaktadır. Ayrıca duygu düzenlemenin cinsiyet açısından farklılaşıp farklılaşmadığına bakılmıştır. Araştırma verileri toplandıktan sonra bilgisayar ortamına aktarılarak analizler için hazır duruma getirilmiştir. Araştırma verilerinin analizinde değişkenlere bağlı olarak SPSS 25.0 paket programı kullanılıp Pearson momentler çarpım korelasyon katsayısı, çoklu regresyon analizi ve bağımsız gruplar t testinden yararlanılmıştır. Verilerin istatistiksel analizi yordayıcı değişkenin bağımlı değişken üzerindeki etkilerini ortaya koyan bir desen içinde ele alınmıştır. Bu araştırmanın yordayıcı değişkeni; öz-şefkat olup bağımlı değişken ise duygu düzenleme düzeyidir. Duygu düzenleme ve öz-şefkat düzeyleri arasındaki ilişkinin analizinde Pearson momentler çarpım korelasyon katsayısı tekniğinden yararlanılmıştır. Özşefkat düzeyinin duygu düzenleme düzeyini yordamasının incelenmesinde çoklu regresyon analizinden yararlanılmıştır. Duygu düzenlemenin cinsiyet açısından incelenmesinde bağımsız gruplar $t$ testinden yararlanılmıştır.

\section{BULGULAR}

\section{Duygu Düzenleme ve Öz-Şefkat Arasındaki İlişkiler}

Katılımcıların duygu düzenleme ve öz-şefkat düzeyleri arasındaki ilişkileri incelemek amacıyla ilgili ölçek ve alt boyutlardan elde ettikleri puanlar arasında hesaplanan korelasyon katsayıları Tablo 1'de verilmiştir.

Tablo 1. Katılımcıların Duygu Düzenleme ve Öz-Şefkat Puanları Arasındaki Korelasyonlar

\begin{tabular}{lllllllllll}
\hline & $\mathbf{1}$ & $\mathbf{2}$ & $\mathbf{3}$ & $\mathbf{4}$ & $\mathbf{5}$ & $\mathbf{6}$ & $\mathbf{7}$ & $\mathbf{8}$ \\
\hline $\begin{array}{l}1 \text { Yeniden } \\
\text { değerlendirme }\end{array}$ & - & & & & & & & & &
\end{tabular}




\begin{tabular}{|c|c|c|c|c|c|c|c|}
\hline 2 Gizleme & $.617 * *$ & - & & & & & \\
\hline 3 Öz-sevecenlik & $.347 * *$ & $.422 * *$ & - & & & & \\
\hline 4 Öz-yargilama & .874 & $-.110^{*}$ & $-.244 * *$ & - & & & \\
\hline $\begin{array}{l}5 \text { Paylaşımların } \\
\text { bilincinde olma }\end{array}$ & $.288 * *$ & $.344 * *$ & $.642 * *$ & -.077 & - & & \\
\hline 6 İzolasyon & .986 & $-.131 * *$ & $-.153 * *$ & $.759 * *$ & -.018 & - & \\
\hline 7 Bilinçlilik & $.349 * *$ & $.424 * *$ & $.678 * *$ & $-.162 * *$ & $.657 * *$ & $-.139 * *$ & - \\
\hline 8 Aşırı özdeşleşme & -.068 & $-.184 * *$ & $-.199 * *$ & $.734 * *$ & -.008 & $.761 * *$ & $-.207 * *$ \\
\hline
\end{tabular}
$* \mathrm{p}<.05 * * \mathrm{p}<.01$

Tablo 1'e bakıldığında duygu düzenlemenin yeniden değerlendirme alt boyutunun öz-şefkatin özsevecenlik $(\mathrm{r}=.347, \mathrm{p}<.01)$ ve bilinçlilik $(\mathrm{r}=.349, \mathrm{p}<.01)$ alt boyutları ile orta düzeyde pozitif yönlü, paylaşımların bilincinde olma $(\mathrm{r}=.288, \mathrm{p}<.01)$ alt boyutu ile de düşük düzeyde pozitif yönlü ilişki bulunmuştur. Duygu düzenlemenin gizleme alt boyutunun öz sevecenlik $(\mathrm{r}=.422, \mathrm{p}<.01)$, paylaşımların bilincinde olma $(\mathrm{r}=.344, \mathrm{p}<.01)$ ve bilinçlilik $(\mathrm{r}=.424$, $\mathrm{p}<.01)$ düzeyleri ile orta düzeyde pozitif yönlü, özyargılama $(\mathrm{r}=-.110, \mathrm{p}<.05)$, izolasyon $(\mathrm{r}=.-131, \mathrm{p}<.01)$ ve aşırı özdeşleşme $(\mathrm{r}=-.184, \mathrm{p}<.01)$ düzeyleri ile de düşük düzeyde negatif yönlü ilişki bulunmuştur.

\section{Öz-Şefkatin Duygu Düzenlemeyi Yordamadaki Rolüne İlişkin Bulgular}

Öz-şefkatin duygu düzenlemenin yeniden değerlendirme alt boyutu üzerindeki etkisini incelemek amacıyla yürütülen çoklu regresyon analizi sonuçları Tablo 2'de gösterilmiştir.

Tablo 2. Öz-Şefkatin Duygu Düzenlemenin Yeniden Değerlendirme Alt Boyutunu Yordamasına İlişkin Çoklu Regresyon Analizi Sonuçları

\begin{tabular}{lccccc}
\hline Model & B & SH & $\boldsymbol{\beta}$ & $\mathbf{t}$ & $\mathbf{p}$ \\
\hline Sabit & 14.349 & 2.041 & - & 7.030 & .000 \\
Öz-sevecenlik & .367 & .115 & .218 & 3.183 & .002 \\
Öz-yargılama & .240 & .113 & .164 & 2.116 & .035 \\
Paylaşımların bilincinde olma & .090 & .138 & .044 & .654 & .514 \\
İzolasyon & .072 & .140 & .041 & .513 & .608 \\
Bilinçlilik & .386 & .153 & .176 & 2.528 & .012 \\
Aşırı özdeşleşme & -.247 & .139 & -.139 & -1.775 & .077 \\
\hline R=.401, $\mathrm{R}^{2}=.161, F_{(6-404)}=12.687, \mathrm{p}=.000$ & & & & \\
\hline
\end{tabular}

Oluşturulan regresyon modelinin anlamlı olduğu tespit edilmiştir $(F(6-404)=12.69, p<.001)$. Özşefkatin duygu düzenlemenin yeniden değerlendirme alt boyutuna ilişkin varyansın \%16.1'ini açıklamaktadır $\left(\mathrm{R}^{2}=.161\right)$. Standardize edilmiş regresyon katsayısına $(\beta)$ göre, yordayıcı değişkenlerin yeniden değerlendirme üzerindeki göreli önem sırası; Öz-sevecenlik, bilinçlilik, öz-yargılama, aşırı 
özdeşleşme, paylaşımların bilincinde olma ve izolasyondur. Regresyon katsayılarının anlamlılığına ilişkin sonuçlar incelendiğinde ise öz-sevecenlik $(\beta=.22, \mathrm{t}=3.18, \mathrm{p}<.01)$, bilinçlilik $(\beta=.18, \mathrm{t}=2.53, \mathrm{p}<.05)$ ve özyargılamanın $(\beta=.16, \mathrm{t}=2.11, \mathrm{p}<.05)$ yeniden değerlendirme üzerinde önemli (anlamlı) bir yordayıc1 olduğu görülmektedir. Aşırı özdeşleşme $(\beta=-.14, \mathrm{t}=-1.77, \mathrm{p}>.05)$, paylaşımların bilincinde olma $(\beta=.04$, $\mathrm{t}=.65, \mathrm{p}>.05)$ ve izolasyon $(\beta=.04, \mathrm{t}=.51, \mathrm{p}>.05)$ ise önemli bir etkiye sahip değildir.

Öz-şefkatin duygu düzenlemenin gizleme alt boyutu üzerindeki etkisini incelemek amaciyla yürütülen çoklu regresyon analizi sonuçları Tablo 3'te gösterilmiştir.

Tablo 3. Öz-Şefkatin Duygu Düzenlemenin Gizleme Alt Boyutunu Yordamasına İlişkin Çoklu Regresyon Analizi Sonuçları

\begin{tabular}{llllll}
\hline Model & B & SH & $\boldsymbol{\beta}$ & $\mathbf{t}$ & $\mathbf{p}$ \\
\hline Sabit & 12.321 & 1.128 & - & 10.927 & .000 \\
Öz-sevecenlik & .228 & .064 & .235 & 3.576 & .000 \\
Öz-yargılama & .120 & .063 & .143 & 1.923 & .055 \\
Paylaşımların bilincinde olma & .082 & .076 & .069 & 1.074 & .284 \\
İzolasyon & -.051 & .077 & -.051 & -.662 & .508 \\
Bilinçlilik & .256 & .084 & .203 & 3.034 & .003 \\
Aşırı özdeşleşme & -.166 & .077 & -.162 & -2.157 & .032 \\
\hline
\end{tabular}

$\mathrm{R}=.479, \mathrm{R}^{2}=.229, \mathrm{~F}(6-404)=19.753, \mathrm{p}=.000$

Oluşturulan regresyon modelinin anlamlı olduğu tespit edilmiştir $(F(6-404)=19.75, p<.001)$. Özşefkatin duygu düzenlemenin gizleme alt boyutuna ilişkin varyansın \%22.9'unu açıklamaktadır $\left(\mathrm{R}^{2}=.229\right)$. Standardize edilmiş regresyon katsayısına $(\beta)$ göre, yordayıcı değişkenlerin gizleme üzerindeki göreli önem sırası; Öz-sevecenlik, bilinçlilik, aşırı özdeşleşme, öz-yargılama, paylaşımların bilincinde olma ve izolasyondur. Regresyon katsayılarının anlamlılığına ilişkin sonuçlar incelendiğinde ise özsevecenlik $(\beta=.23, \mathrm{t}=3.58, \mathrm{p}<.001)$, bilinçlilik $(\beta=.20, \mathrm{t}=3.03, \mathrm{p}<.01)$ ve aşırı özdeşleşmenin $(\beta=-.16, \mathrm{t}=-$ $2.16, p<.05)$ gizleme üzerinde önemli (anlamlı) bir yordayıcı olduğu görülmektedir. Öz-yargılama $(\beta=.14$, $\mathrm{t}=1.92, \mathrm{p}>.05)$, paylaşımların bilincinde olma $(\beta=.07, \mathrm{t}=1.07, \mathrm{p}>.05)$ ve izolasyon $(\beta=-.05, \mathrm{t}=-.66, \mathrm{p}>.05)$ ise önemli bir etkiye sahip değildir.

\section{Duygu Düzenlemenin Cinsiyet Açısından İncelenmesi}

Yurtta kalan üniversite öğrencilerinin duygu düzenleme düzeylerinin cinsiyete göre farklılaşıp farklılaşmadığına ilişkin bağımsız gruplar $\mathrm{t}$ testi sonuçları Tablo 4'te verilmiştir.

Tablo 4. Yurtta Kalan Üniversite Öğrencilerinin Duygu Düzenleme Düzeylerinin Cinsiyete Göre t-testi Sonuçları

\begin{tabular}{|c|c|c|c|c|c|c|}
\hline Alt Boyutlar & Cinsiyet & $\mathbf{N}$ & $\overline{\mathbf{x}}$ & SS & $\mathbf{t}$ & $\mathbf{p}$ \\
\hline Yeniden Değerlendirme & Kadın & 260 & 27.39 & 7.85 & -2.96 & .003 \\
\hline
\end{tabular}




\begin{tabular}{lllllll}
\hline & Erkek & 145 & 29.58 & 5.60 & & \\
\hline \multirow{2}{*}{ Gizleme } & Kadın & 260 & 19.54 & 4.42 & \multirow{2}{*}{0.90} & \multirow{2}{*}{.058} \\
& Erkek & 145 & 20.36 & 3.56 & & \\
\hline
\end{tabular}

Yurtta kalan üniversite öğrencilerinin yeniden değerlendirme düzeyleri ile cinsiyetleri arasında anlamlı bir farklılık olup olmadığ yapılan $\mathrm{t}$ testi ile analiz sonucunda yurtta kalan üniversite öğrencilerinin yeniden değerlendirme düzeyleri ile cinsiyetleri arasında anlamlı bir farklılık bulunmuştur $(\mathrm{t}=-2.96, \mathrm{p}<.05) . \mathrm{Bu}$ bulgudan hareketle, erkeklerin $(\overline{\mathrm{x}}=29.58)$ kadınlara $(\overline{\mathrm{x}}=27.39)$ göre yeniden değerlendirme düzeylerinin daha yüksek olduğu görülmektedir. Gizleme düzeyleri ile cinsiyetleri arasında anlamlı bir farklılık olup olmadığ yapılan t testi ile analiz sonucunda yurtta kalan üniversite öğrencilerinin gizleme düzeyleri ile cinsiyetleri arasında anlamlı bir farklılık bulunmamıştır $(\mathrm{t}=-1.90$, $\mathrm{p}>.05)$.

\section{TARTIŞMA VE SONUÇ}

Alanyazın taraması yapıldığında, öz-şefkat ve duygu düzenleme değişkenlerinin birlikte ele alındığı araştırmalar mevcuttur ve aşağıda bunlara değinilmiştir. Ayrıca, tartışmanın zenginleştirilmesi için araştırma konusu ile ilişkili olabilecek benzer araştırmaların sonuçlarına da yer verilmiştir. Duygu düzenlemenin bireylerin günlük yaşam olayları içerisinde olumlu bir etkisi olup duygu düzenlemeyle ilişkili olabilecek değişkenler vardır. Bu çalışmada, yurtta kalan üniversite öğrencilerinin duygu düzenleme ile öz-şefkat düzeyleri arasındaki ilişkinin incelenmesi, öz-şefkatin duygu düzenlemeye ilişkin varyansın ne kadarını yordadığı ve duygu düzenlemenin cinsiyet açısından incelenmesine dair elde edilen sonuçlar tartışılmıştır.

Araştırma sonucunda, duygu düzenleme ile öz-şefkat düzeyleri arasındaki ilişkilere ilişkin bulgular incelendiğinde duygu düzenlemenin yeniden değerlendirme alt boyutunun öz-şefkatin öz-sevecenlik, paylaşımların bilincinde olma ve bilinçlilik alt boyutlarıyla pozitif ilişkili; gizleme alt boyutunun ise özşefkatin öz-sevecenlik, paylaşımların bilincinde olma ve bilinçlilik alt boyutlarıyla pozitif, öz-yargılama, izolasyon ve aşırı özdeşleşme alt boyutlarıyla ise negatif ilişkili olduğu sonucu bulunmuştur. Burada gizleme alt boyutu ile negatif ilişkili çıkanlar öz-şefkatin olumlu alt boyutlarının karşısında yer alan olumsuz alt boyutlardır. Araştırmanın sonucunu destekleyen çalışmalar bulunmaktadır. Diedrich, Burger, Kirchner ve Berking (2016) tarafından yapılan bir araştırma sonucuna göre duygu düzenleme ile öz-şefkat arasında pozitif bir ilişki bulunmuştur. Vatan (2019a, 2019b) duygu düzenleme ile öz-şefkat arasındaki ilişkinin önemli olabileceğine dikkat çekmiştir ve duygu düzenlemede öz-şefkatin önemli bir rolünün olduğu düşünülmektedir.

Öz-şefkatin alt boyutu olan bilinçlilik (bilinçli farkındalık) ile duygu düzenleme arasında ilişkinin olduğu çalışmalar vardır. Bu araştırmada bilinçlilik ile duygu düzenleme arasında pozitif ilişki bulunmuş olup bu sonucu destekleyen çalışmalar bulunmaktadır (Toprak ve Çetiner-Bacak, 2019). Bilinçli farkındalık ile duygu düzenlemenin alt boyutu olan yeniden değerlendirme arasında pozitif ilişkinin olduğu araştırmalar da vardır (Desrosiers, Vine, Klemanski ve Nolen-Hoeksema, 2013; Karabacak ve Demir, 2017). Bu sonuçlardan hareketle, bireyler kendilerine nazikçe ve sevecen bir tavırla yaklaşıp özsevecenliklerini artırarak ve şu anda kalarak olan bitenin farkındalığını yaşayıp bilinçliliklerini artırarak duygularını yakından tanıyı onları anlamlandırabildikleri ve duygularına daha iyi odaklanabildikleri düşünülebilir ve böylece duygularını yeniden değerlendirerek, duygularını daha iyi düzenleyebildiklerinden bahsedilebilir.

Literatüre bakıldığında, duygu düzenleme güçlüğü ile öz-şefkatin ya da bilinçli farkındalığın birlikte olduğu çalışmalar vardır. Duygu düzenleme güçlüğü kavramı, alanyazın incelendiği zaman bireyin ruh sağılığı açısından olumsuz bir durumdur (Linehan, 1993; Sheppes, Suri ve Gross, 2015). 
Dolayısıyla duygu düzenleme güçlüğünün, öz-şefkatle ve bilinçli farkındalıkla ilişkisinin negatif olduğunu gösteren araştırmalar bulunmaktadır. Yapılan araştırmalarda duygu düzenleme güçlüğü ile özşefkat arasında negatif bir ilişki bulunmuştur (Aktaş, 2017; Finlay-Jones, Rees ve Kane, 2015; Scoglio ve diğ., 2015). Bilinçli farkındalık ve duygu düzenleme güçlüğünün yer aldığı araştırmalarda iki değişken arasında negatif bir ilişki vardır (Gündüz, 2016; Luberto, Cotton, McLeish, Mingione ve Bryan, 2014). $\mathrm{Bu}$ sonuçlardan hareketle bireylerin öz-şefkat ya da bilinçli farkındalık düzeyleri azaldıkça duygu düzenleme güçlüğünün arttığı söylenebilir. Bireyin günlük yaşamında, kendisine gösterdiği şefkatin ve farkındalı̆̆ının azalmasıyla rahatsızlık uyandıran duygularını sağlıkı bir şekilde değerlendiremeyip ve onları anlamlandıramayıp onların etkisinde kalabileceği ve böylece duygularını düzenlemede güçlükler yaşayabileceği düşünülebilir.

Çoklu regresyon analizleri sonuçlarına göre öz-şefkat, duygu düzenlemeyi anlamlı olarak yordamaktadır. Öz-şefkatin alt boyutlarından özellikle bilinçlilik ve öz-sevecenlik, duygu düzenleme üzerinde önemli bir yordayıcıdır. Vatan (2019a) öz-şefkatin duygu düzenleme becerilerinde önemli bir rolünün olduğu düşüncesinden yola çıkarak, kişinin kendisine sevecen, nazik ve şefkatle yaklaşmasıyla ve bilinçliliğiyle duygu düzenleme becerilerinin bunlardan olumlu etkileneceğini düşünmektedir. Neff’e göre (2003b) öz-şefkat ve alt boyutu olan bilinçlilik ile birey, rahatsız edici ve can sıkıcı duygulardan kaçınmadan yaşadığı anın farkında olarak ve kendisine şefkatle ve anlayışla yaklaşarak bu duyguların düzenlenmesini sağlar. Böylece birey, bu durumu avantaja çevirerek kendisinin tarafinda tutar. Görüldügü üzere, araştırma sonucu ve yukarıdaki bilgiler 1şığında öz-şefkatin; özellikle de bilinçlilik ve öz-sevecenlik alt boyutlarının, bireylerin duygu düzenleme beceri düzeylerini olumlu etkilediği söylenebilir.

Duygu düzenlemenin cinsiyete göre olan bulguları incelendiğinde yeniden değerlendirme alt boyutunun erkeklerde anlamlı olarak daha yüksek olduğu bulunmuştur. Gizleme alt boyutu ise cinsiyete göre farklılaşmamaktadır. Alanyazına bakıldığında ergenlerle yapılan bir araştırma sonucuna göre duygu düzenleme becerileri erkeklerde daha yüksek olduğu bulunmuştur (Demireğen, 2019). Okul öncesi çocukları ile yapılan çalışma sonuçlarına göre duygu düzenleme becerileri cinsiyete göre farklılık göstermemektedir (Bozkurt-Yükçü ve Demircioğlu, 2017; Carlson ve Wang, 2007). Bu sonuçlar gösteriyor ki duygu düzenleme becerilerinin cinsiyet açısından farkl1lı göstermesi ya da göstermemesi çalışılan grubun özellikleri, katılımcı sayısı, katılımcıların gelişimsel dönemi, katılımcıların yaşadığ çevre ve sahip olduğu kültür vs. gibi durumlardan kaynaklanabildiği düşünülmektedir. Bu çalışmada duygu düzenlemenin yeniden değerlendirme alt boyutunun erkeklerde daha yüksek olmasında; katılımcıların üniversite öğrencisi olup yurtta kalanlarla sınırlı tutulması, katılımcıların aile yaşantısı ve yetiştirilme tarzı vs. etkili olabilir.

\section{ÖNERILER}

Sonuç olarak, araştırmada yurtta kalan üniversite öğrencilerinin duygu düzenleme ile öz-şefkat düzeyleri arasında anlamlı bir ilişki bulunmuş ve öz-şefkat düzeyinin, duygu düzenleme düzeyini anlamlı olarak yordadığı sonucuna ulaşılmıştır. Son yıllarda, bu konuyla ilgili araştırmalar yürütülmektedir ve araştırma sonuçlarının zenginleştirilmesi için yeni ve farklı araştırmaların yürütülmesi faydalı olabilir. Bununla birlikte, bu araştırma üniversite öğrencileriyle yapıldığından dolayı farklı gelişim dönemlerinde bulunan kişilerle de bu konuyla ilgili çalışmalar yapılabilir. Duygu düzenlemeye anlamlı bir etkisinin olduğu görülen öz-şefkatin üniversite öğrencilerinde (özellikle öz-şefkat düzeyi düşük olanlar) arttırılmasına yönelik çalışmalar yapılabilir.

\section{KAYNAKÇA}

Akın, Ü., Akın, A., \& Abacı, R. (2007). Öz-Duyarlık Ölçeği: Geçerlik ve güvenirlik çalışması. Hacettepe Üniversitesi Eğitim Fakültesi Dergisi, 33(33), 1-10. 
Aktaş, A. (2017). Türkiye örnekleminde, narsisistik özellik, öz-şefkat ve duygu düzenleme güçlüğ̈̈ arasındaki ilişkinin incelenmesi (Yüksek Lisans Tezi). İstanbul Arel Üniversitesi, Sosyal Bilimler Enstitüsü, İstanbul.

Cole, P. M., Martin, S. E., \& Dennis, T. A. (2004). Emotion regulation as a scientific construct: Methodological challenges and directions for child development research. Child Development, 75(2), 317333. doi:10.1111/j.1467-8624.2004.00673.x

Demireğen, Z. (2019). Ergenlik dönemindeki öğrencilerin duygu düzenleme becerileri ile akademik güdülenmeleri arasındaki ilişki (Yüksek Lisans Tezi). Ankara Üniversitesi, Eğitim Bilimleri Enstitüsü, Ankara.

Desrosiers, A., Vine, V., Klemanski, D. H., \& Nolen-Hoeksema, S. (2013). Mindfulness and emotion regulation in depression and anxiety: common and distinct mechanisms of action. Depression and Anxiety, 30, 654661.

Diedrich, A., Burger, J., Kirchner, M., \& Berking, M. (2016). Adaptive emotion regulation mediates the relationship between self-compassion and depression in individuals with unipolar depression. Psychology and Psychotherapy: Theory, Research and Practice, 90(3), 247-263.

Eldeleklioğlu, J., \& Eroğlu, Y. (2015). A Turkish adaptation of the Emotion Regulation Questionnaire. International Journal of Human Sciences, 12(1), 1157-1168.

Finlay-Jones, A. L., Rees, C. S., \& Kane, R. T. (2015). Self-compassion, emotion regulation and stress among Australian psychologists: Testing an emotion regulation model of self-compassion using structural equation modeling. PLOS One, 10(7), 1-19.

Gilbert, P. (2010). Compassion focused therapy: Distinctive features. The CBT distinctive features series. New York: Routledge.

Goleman, D. (1996). Duygusal zekâ (Çev. B. S. Yüksel). İstanbul: Varlık Yayınları.

Gökçen, G. (2015). Madde kullanan ve kullanmayan üniversite ögrencilerinin psikolojik dayanıklılık düzeylerinin incelenmesi (Yayınlanmamış Yüksek Lisans Tezi). Akdeniz Üniversitesi, Eğitim Bilimleri Enstitüsü, Antalya.

Gratz, K. L., \& Roemer, L. (2004). Multidimensional assessment of emotion regulation and dysregulation: Development, factor structure, and initial validation of the difficulties in emotion regulation scale. Journal of Psychopathology and Behavioral Assessment, 26, 41-54.

Gross, J. J. (1998). The emerging field of emotion regulation: An integrative review. Review of General Psychology, 2(3), 271-299. doi:10.1037/1089-2680.2.3.271

Gross, J. J., \& Munoz, R. F. (1995). Emotion regulation and mental health. Clinical Psychology: Science and Practice, 2, 151-164.

Gross, J. J., \& Thompson, R. A. (2007). Emotion regulation: Conceptual foundations. In J. J. Gross (Ed.), Handbook of emotion regulation (p. 3-24). The Guilford Press.

Gündüz, H. (2016). Yetişkinlerde bilinçli farkındalık (mindfulness) ve duygu düzenleme arasındaki ilişki (Yüksek Lisans Tezi). Nişantaşı Üniversitesi, Sosyal Bilimler Enstitüsü, İstanbul.

Karabacak, A., \& Demir, M. (2017). Özerklik, bağlanma stilleri, bilinçli farkındalık ve duygu düzenleme arasındaki ilişkilerin incelenmesi. Bayburt Eğitim Fakültesi Dergisi, 12(23), 271-291.

Karaçay, B. (2018). Mutlu beyin. Ankara: Tübitak.

Karasar, N. (2016). Bilimsel araştırma yöntemi (31. Baskı). Ankara: Nobel Yayınları.

Leahy, R. L., Tirch, D., \& Napolitano, L. A. (2011). Emotion regulation in psychotherapy: A practitioner's guide. NY: The Guildford Press.

Linehan M. (1993). Cognitive-behavioral treatment of borderline personality disorders. New York, USA: Guilford Press.

London, M. (1997). Overcoming career barriers: A model of cognitive and emotional processes for realistic appraisal and constructive coping. Journal of Career Development, 24(1), 25-38.

Luberto, C. M., Cotton, S., McLeish, A. C., Mingione, C. J., ve O’Bryan, E. M. (2014). Mindfulness skills and emotion regulation: The mediating role of coping self-efficacy. Mindfulness, 5(4), 373-380.

Neff, K. D. (2003a). Self-compassion: An alternative conceptualization of a healthy attitude toward oneself. Self and Identity, 2(2), 85-102.

Neff, K. D. (2003b). The development and validation of a scale to measure self-compassion. Self and Identity, 2(3), 223-250. 
Niendental, P, Krauth-Gruber, S., \& Ric, F. (2006). Psychology of emotion: Interpersonal, experiential, and cognitive approaches. New York: Psychology Press.

Scoglio, A. A., Rudat, D. A., Garvert, D., Jarmolowski, M., Jackson, C., \& Herman, J. L. (2015). Selfcompassion and responses to trauma: The role of emotion regulation. Journal of Interpersonal Violence, 33(13), 2016-2036.

Sheppes, G., Suri, G., \& Gross, J. J. (2015). Emotion regulation and psychopathology. Annual Review of Clinical Psychology, 11, 379-405.

Sürücü, M., \& Bacanlı, F. (2010). Üniversiteye uyumun psikolojik dayanıklılık ve demografik değişkenlere göre incelenmesi. Gazi Üniversitesi Gazi Ĕ̆itim Fakültesi Dergisi, 30(2), 375-396.

TDK (Türk Dil Kurumu). (2019). Güncel Türkçe Sözlük, http://www.tdk.gov.tr adresinden alınmıştır.

Thompson, R. A. (2008). Emotion regulation: A theme in search of definition. Monographs of the Society for Research in Child Development, 59(2-3), 25-52. doi:10.1111/j.1540-5834.1994.tb01276.x

Toprak, Z., \& Çetiner Bacak, S. (2019). Ortaokul öğrencilerinin duygu düzenleme becerileri ile bilinçli farkındalık düzeyleri arasındaki ilişkinin incelenmesi. Yaşadıkça Eğitim, 33(2), 306-317.

Vatan, S. (2019a). Duygu düzenlemenin şah damarı: Öz-şefkat. Pivolka, 9(31), 2-4.

Vatan, S. (2019b). Duygu düzenleme becerilerinin değerlendirilmesi ve geliştirilmesi için duygu düzenleme eğitiminin uygulanması. Proje No: Hacettepe Üniversitesi Bilimsel Araştırmalar Koordinatörlüğü SHD 13888.

Werner, K. H., \& Gross, J. J. (2010). Emotion regulation and psychopathology: A conceptual framework. In A. Kring \& D. Sloan (Eds.), Emotion regulation and psychopathology: A transdiagnostic approach to etiology and treatment (pp. 13-37). New York, NY: Guilford.

Yıldırım, M., \& Sarı, T. (2018). Öz-Şefkat Ölçeği Kısa Formu'nun Türkçe uyarlaması: Geçerlik ve güvenirlik çalışması. Abant İzzet Baysal Üniversitesi Eğitim Fakültesi Dergisi, 18(4), 2502-2517.

Yıldırım, N. (2014). Başarılı öğrenciler açısından yurtlar. Ĕgitime Bakış, Eğitim-Öğretim ve Bilim Araştırma Dergisi, 30, 19-23. 


\section{EXTENDED ABSTRACT}

\section{Introduction}

When they started their university life many of the students leave the city where they were born and where they completed their primary and secondary education and live in an area away from their family. Young people, whose new living space is dormitories, face some problems and responsibilities (Sürücü and Bacanl1, 2010). In this period, students are expected to be individuals who can cope with their problems, are aware of environmental and internally protective factors, actively participate in life, use communication skills and apply these for their purposes (Gökçen, 2015). It's thought that emotion regulation and self-compassion have important roles in university students' fulfillment of these expectations.

Based on the information above, the aim of this study is to examine the relationship between emotion regulation and self-compassion levels of university students living in the dormitory. Within the scope of this research, answers to the following questions are sought.

1. Is there a significant relationship between emotion regulation and self-compassion levels of university students living in the dorm?

2. Do the self-compassion levels of the university students staying at the dormitory significantly predict their emotional regulation levels?

3. Do emotion regulation levels of university students living in dormitories differ significantly by gender?

\section{METHOD}

\section{Working group}

Research was carried out in 2018-2019 academic year with a total of 405 people, 260 (64.2\%) women and $145(35.8 \%)$ men aged between $18-27$, who voluntarily participated to the study among the university students staying at Konya KTO Education and Health Foundation dormitories.

\section{Data Collection Tools}

\section{Personal Information Form}

In order to collect some personal information from the participants, questions regarding their gender, age and education levels of the participants were asked.

\section{Emotion Regulation Scale}

Adaptation of this scale, which was developed by John and Gross (2003) into Turkish, was carried out by Eldeleklioğlu and Eroğlu (2015). The scale consists of 7 Likert-type 10 items. The Cronbach Alpha coefficient was found .78 for the reappraisal sub-dimension and .73 for the suppression sub-dimension.

\section{Self-Compassion Scale}

The self-compassion scale developed by Neff (2003b), consists of 26 items and 6 sub-dimensions. Subdimensions are self-judgment, being aware of the sharings, isolation, consciousness, self-love and excessive identification. The scale has a 5-point Likert-type rating. The validity and reliability studies of the scale in Turkish were carried out by Akın, Akın and Abacı (2007). Exploratory factor analysis (AFA) and confirmatory factor analysis were applied to examine the construct validity of the scale. The internal consistency coefficients of the selfsensitivity Scale are as follows; .77 for self-compassion subscale, .72 for self-judgment, .72 for being aware of the sharings, .80 for isolation, .74 for consciousness, and .74 for excessive identification.

\section{Data Analysis}

Descriptive statistics are calculated for all variables to reveal the relationship between emotion regulation and self-compassion levels of university students living in the dormitory. In addition, it was examined whether emotion regulation differs in terms of gender. After the research data were collected, they were transferred to the computer and made ready for analysis. In the analysis of the research data, SPSS 25.0 package program was used depending 
on the variables and Pearson moments multiplication correlation coefficient, multiple regression analysis and independent groups $t$ test were used.

\section{FINDINGS}

\section{Relationships Between Emotion Regulation and Self-Compassion}

Correlation coefficients calculated between the scores of the participants on the scale and sub-dimensions in order to examine the relationships between emotion regulation and self-compassion levels are given in Table 1.

Table 1. Correlations Between Participants' Emotion Regulation and Self-Compassion Points

\begin{tabular}{|c|c|c|c|c|c|c|c|c|}
\hline & 1 & 2 & 3 & 4 & 5 & 6 & 7 & 8 \\
\hline 1 reappraisal & - & & & & & & & \\
\hline 2 Suppression & $.617 * *$ & - & & & & & & \\
\hline 3 Self-compassion & $.347 * *$ & $.422 * *$ & - & & & & & \\
\hline 4 Self-judgment & .874 & $-.110 *$ & $-.244 * *$ & - & & & & \\
\hline $\begin{array}{l}5 \text { Being aware of the } \\
\text { sharings }\end{array}$ & $.288 * *$ & $.344 * *$ & $.642 * *$ & -.077 & - & & & \\
\hline 6 Isolation & .986 & $-.131 * *$ & $-.153 * *$ & $.759 * *$ & -.018 & - & & \\
\hline 7 Consciousness & $.349^{* *}$ & $.424 * *$ & $.678 * *$ & $-.162 * *$ & $.657 * *$ & $-.139 * *$ & - & \\
\hline 8 Excessive identification & -.068 & $-.184 * *$ & $-.199 * *$ & $.734 * *$ & -.008 & $.761 * *$ & $-.207 * *$ & - \\
\hline
\end{tabular}

$* \mathrm{p}<.05 * * \mathrm{p}<.01$

Considering Table 1 , the sub-dimensions of self-compassion $(r=.347, p<.01)$ and consciousness $(r=.349, p$ $<.01)$ of the reappraisal sub-dimension of emotion regulation are moderately positive; a low level of positive correlation was found with the sub-dimension of awareness $(r=.288, p<.01)$. The level of suppression $(r=.422, p$ $<.01)$, being aware of the sharings $(r=.344, \mathrm{p}<.01)$ and awareness $(\mathrm{r}=.424, \mathrm{p}<.01)$ of the suppression subdimension of emotion regulation positively, with self-judgment $(r=-.110, p<.05)$, isolation $(r=.-131, p<.01)$ and excessive identification $(r=-.184, \mathrm{p}<.01)$ levels a low level negative correlation was found.

\section{Findings on the Role of Self-Compassion in Predicting Emotion Regulation}

The results of multiple regression analysis conducted to examine the effect of self-compassionate on emotional reappraisal sub-dimension are shown in Table 2.

Table 2. Multiple Regression Analysis Results Regarding Self-Compassion Predicting the reappraisal SubDimension of Emotion Regulation

\begin{tabular}{lccccc}
\hline Model & B & SH & B & t & p \\
\hline Constant & 14349 & 2041 & - & 7030 & .000 \\
Self-compassion & .367 & .115 & .218 & 3183 & .002 \\
Self-judgment & .240 & .113 & .164 & 2116 & .035 \\
Being aware of the sharings & .090 & .138 & .044 & .654 & .514 \\
Isolation & .072 & .140 & .041 & .513 & .608 \\
Consciousness & .386 & .153 & .176 & 2528 & .012 \\
Excessive identification & -.247 & .139 & -.139 & -1775 & .077 \\
\hline
\end{tabular}


$\mathrm{R}=.401, \mathrm{R}^{2}=.161, F_{(6-404)}=12.687, \mathrm{p}=.000$

The created regression model was found to be significant $(\mathrm{F}(6-404)=12.69, \mathrm{p}<.001)$. It explains $16.1 \%$ of the variance related to the reappraisal sub-dimension of emotion regulation of self-compassion $\left(\mathrm{R}^{2}=.161\right)$. According to the standardized regression coefficient $(\beta)$, the relative importance order of the predictive variables on reappraisal; self-compassion, consciousness, self-judgment, excessive identification, being aware of the sharings and isolation. When the results related to the significance of the regression coefficients are examined, self-compassion $(\beta=.22, \mathrm{t}=3.18, \mathrm{p}<.01)$, consciousness $(\beta=.18, \mathrm{t}=2.53, \mathrm{p}<.05)$ and self-judgment $(\beta=.16, \mathrm{t}=2.11, \mathrm{p}<.05)$ appears to be an important (significant) predictor of reappraisal . Excessive identification $(\beta=-.14, t=-1.77, p>$ $.05)$, being aware of the sharings $(\beta=.04, \mathrm{t}=.65, \mathrm{p}>.05)$ and isolation $(\beta=.04, \mathrm{t}=.51, \mathrm{p}>.05)$ does not have a significant effect .

The results of multiple regression analysis conducted to examine the effect of self-compassion on the suppression sub-dimension of emotion regulation are shown in Table 3.

Table 3. Multiple Regression Analysis Results of Self-Compassion Predicting the Hiding Sub-Dimension of Emotion Regulation

\begin{tabular}{llllll}
\hline Model & B & SH & B & t & p \\
\hline Constant & 12321 & 1128 & - & 10927 & .000 \\
Self-compassion & .228 & .064 & .235 & 3576 & .000 \\
Self-judgment & .120 & .063 & .143 & 1923 & .055 \\
Being aware of the shares & 0.82 & .076 & .069 & 1074 & .284 \\
Isolation & -.051 & .077 & -.051 & -.662 & .508 \\
Consciousness & .256 & .084 & .203 & 3034 & .003 \\
Excessive identification & -.166 & .077 & -.162 & -2157 & .032
\end{tabular}

$\mathrm{R}=.479, \mathrm{R}^{2}=.229, \mathrm{~F}(6-404)=19.753, \mathrm{p}=.000$

The regression model created was found to be significant $(\mathrm{F}(6-404)=19.75, \mathrm{p}<.001)$. It explains $22.9 \%$ of the variance related to the suppression sub-dimension of self-compassion emotion regulation $\left(\mathrm{R}^{2}=.229\right)$. According to the standardized regression coefficient $(\beta)$, the relative importance order of the predictive variables on concealment; self-compassion, consciousness, excessive identification, self-judgment, being aware of the shares and isolation. When the results related to the significance of the regression coefficients are examined, self-compassion ( $\beta$ $=.23, \mathrm{t}=3.58, \mathrm{p}<.001)$, consciousness $(\beta=.20, \mathrm{t}=3.03, \mathrm{p}<.01)$ and excessive identification $(\beta=-.16, \mathrm{t}=-2.16, \mathrm{p}$ $<.05)$ appears to be an important (significant) predictor on suppression. Self-judgment $(\beta=.14, t=1.92, p>.05)$, being aware of the shares $(\beta=.07, \mathrm{t}=1.07, \mathrm{p}>.05)$ and isolation $(\beta=-.05, \mathrm{t}=-.66, \mathrm{p}>.05)$ does not have a significant effect.

\section{Investigation of Emotion Regulation in terms of Gender}

Independent groups t test results regarding whether the emotion regulation levels of university students staying at the dormitory differ according to gender are given in Table 4.

Table 4. T-test Results of the Emotion Regulation Levels of University Students in Dormitories by Gender

\begin{tabular}{lllllll}
\hline Sub Dimensions & Gender & N & $\mathbf{x}^{-}$ & SS & t & p \\
\hline Reappraisal & Woman & 260 & 27.39 & 7.85 & -2.96 & .003 \\
\hline
\end{tabular}




\begin{tabular}{|c|c|c|c|c|c|c|}
\hline & & & & & & \\
\hline & Male & 145 & 29.58 & 5.60 & & \\
\hline & Woman & 260 & $19: 54$ & $4: 42$ & & \\
\hline 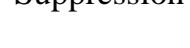 & Male & 145 & $20: 36$ & $3: 56$ & 1.20 & \\
\hline
\end{tabular}

Whether there is a significant difference between the reappraisal levels and the gender of the university students staying in the dormitory, the t test performed showed a significant difference between the reappraisal levels and the gender of the university students staying in the dormitory $(\mathrm{t}=-2.96, \mathrm{p}<.05)$. Based on this finding, it is seen that men $(\overline{\mathrm{x}}=29.58)$ have higher reappraisal levels than women $(\overline{\mathrm{x}}=27.39)$. whether there is a significant difference between suppression levels and their gender, as a result of the analysis with the test, there was no significant difference between the suppression levels and gender of the university students staying in the dormitory $(t=-1.90$, p> .05).

\section{DISCUSSION AND CONCLUSION}

In this study, the relationship between emotion regulation and self-compassion levels of university students living in the dorm was examined. When the findings regarding the relationship between emotion regulation and selfcompassion levels are examined, it is positively associated with the sub-dimensions of self-compassion, being aware of the shares and consciousness of the reappraisal sub-dimension of emotion regulation; the concealment subdimension was found to be positively associated with the sub-dimensions of self-compassion, being aware of the shares and consciousness, and negatively with the sub-dimensions of self-judgment, isolation and excessive identification. According to the results of multiple regression analysis, self-compassion predicts emotion regulation significantly. When the literature is examined, there is no study that discusses the relationship between these two variables. However, there are studies that these two variables may be related (Vatan,2019a, 2019b). In this research, a positive relationship was found between consciousness and reappraisal, and there are studies supporting this result. When the findings of emotion regulation by gender were examined, the sub-dimension of reappraisal was found to be significantly higher in men. The hiding sub-dimension does not differ by gender. According to a literature study, it was found that emotion regulation skills were higher in males (Demireğen, 2019). As a result, it was found that there was a significant relationship between emotion regulation and self-compassion levels of university students living in the dormitory and it was concluded that self-compassion level predicted emotion regulation level significantly.

\section{SUGGESTIONS}

In order to enrich the results related to this subject, new studies can be conducted with individuals in different developmental stages. Programs can be developed to increase self-compassion among university students, which seems to have a meaningful effect on emotion regulation. 